\title{
Do We Deserve Credit for Everything We Understand?
}

\author{
Federica Isabella Malfatti (D) \\ University of Innsbruck, Innsbruck, Austria \\ Email: fede.malfatti89@gmail.com
}

(Received 29 October 2020; revised 2 March 2021; accepted 8 March 2021)

\begin{abstract}
It is widely acknowledged in the literature in social epistemology that knowledge has a social dimension: we are epistemically dependent upon one another for most of what we know. Our knowledge can be, and very often is, grounded on the epistemic achievement of somebody else. But what about epistemic aims other than knowledge? What about understanding? Prominent authors argue that understanding is not social in the same way in which knowledge is. Others can put us in the position to understand, but when we understand something, this accomplishment is to be credited mainly if not entirely to us, as it is due to the successful exercise of our own cognitive abilities. In this paper, I show that the social dimension of understanding closely resembles the social dimension of knowledge. I distinguish between three different ways in which a subject can depend upon another subject for (either the acquisition or the possession of) a certain epistemic good. I then argue that all these kinds of epistemic dependence apply to knowledge and understanding alike. If I am right, understanding is not (always) an achievement to be (mainly) credited to the single epistemic agent who understands.
\end{abstract}

Keywords: Knowledge; understanding; epistemic dependence; division of epistemic labor

\section{Introduction}

Football World Cup 2006. Italy plays against Germany. With two minutes remaining on the clock and the game still goalless, Andrea Pirlo, Italy's central midfielder, dribbles around four players of the opposing team, spots a very tiny window between two defenders and shoots the absolute perfect assist. Fabio Grosso magnificently stops the ball and scores, leading Italy to victory and to the World's Cup final. Who deserves the credit for such an achievement? Who is the stunning goal to be credited to? These questions are not as easy to answer as it might seem. Of course, there is a sense in which the achievement, i.e., the goal, is Grosso's and nobody else's. Grosso was the one who stopped the ball, kicked it with the right combination of strength and precision and sent it directly into the top corner. And yet Pirlo's assist was astonishingly good, and incredibly difficult. There probably would not have been any goal without Pirlo's outstanding performance. Nearly any other player would have probably failed in passing the ball to Grosso in those or similar circumstances. So, although it was Grosso who eventually scored, his achievement seems to be substantially grounded on the successful terms of the Creative Commons Attribution licence (http://creativecommons.org/licenses/by/4.0/), which permits unrestricted re-use, distribution, and reproduction in any medium, provided the original work is properly cited. 
performance of (at least one of) his teammate(s). Football is a team sport, so it is natural to assume that when things work out nicely and the ball hits the goal, there is no single player who deserves the whole credit. The credit is typically shared, i.e., it is spread across the whole team (or part of it).

Epistemologists have long acknowledged that the epistemic goal we call "knowledge" is, or at least can be and very often is, very much like a goal scored on a football field. If we were to rely exclusively on our own (epistemic) strength in our quest of knowledge for example, if we were to accept only those contents that we are in the position to personally justify - we would know extremely little about reality. We would know extremely little - if anything - about our planet, our history, our family members, maybe even ourselves. "Our lives", as Lackey (2008: 1) puts it, "would be unrecognizable”. Elgin (1996: 111) writes:

Much of what I purport to know, I cannot personally justify. I am convinced, for example, that water is $\mathrm{H}_{2} \mathrm{O}$, that Tolstoy wrote War and Peace .... Yet I can say little to justify these claims. ... If I am solely responsible for the epistemic standing of my commitments, I am often on shaky grounds.

And yet our grounds are often not as shaky as it might seem at first sight, because we are social creatures and because knowledge allows for a division of epistemic labor. Much of what we individual epistemic agents know about reality is grounded on, depends upon the achievement or the epistemic performance of someone else. "Rather than relying exclusively on considerations in my ken, I draw on the expertise of others, and they in turn draw on mine" (Elgin 1996: 114; see also Elgin 2017: 120). The fact, for example, that a competent and trustworthy member of our epistemic community firmly believes a certain content can provide us with excellent reasons to believe this content as well. We can thus be justified in believing that $p$ even if somebody else has access to the evidence speaking for $p$ 's truth (Hardwig 1985: 342). The credit for our knowledge, thus, can be and very often is spread across the epistemic community (Lackey 2007: 352).

But what about epistemic goals other than knowledge? Knowledge is certainly a very important aim, and yet in many domains we are not satisfied in collecting justified beliefs about isolated items of fact. We also want to understand the subject matter of what we believe. We want to understand, for example, the phenomenon of antibiotic resistance, the structure of dark matter, the rise in temperatures on our planet, the spread of COVID-19, the mood swings of our partner, and so on. Does understanding allow for a division of epistemic labor as knowledge does? Can our understanding, like our knowledge, be grounded on the epistemic achievement or the epistemic performance of somebody else?

Prima facie, it seems simply undeniable that understanding phenomena of reality is no solipsistic enterprise. Sometimes we make sense of phenomena with our own (epistemic) strength, relying on our reasoning capacities and nothing else. Way more often, however, we need other epistemic agents to guide us in the process of coming to understand (this has been acknowledged, among others, by Jäger 2016; Boyd 2017; Elgin 2017: 111; Gordon 2017; Croce 2018; Grimm 2020; Jäger and Malfatti 2020; Malfatti 2020). Suppose I am struggling in making sense of the fact that the mortality rate related to the COVID-19 infection is much higher in Italy than it has been in China. It would be reasonable for me to reach out to an epistemically superior subject and ask her: Why? Why is this particular thing happening? Should I have expected this? Why am I not expecting this? What will happen next? Given that my interlocutor is reliable, 
competent, and trustworthy, she will typically guide me out of the puzzlement and help me gain understanding. It seems thus as if:

DEP We do not only depend epistemically upon other epistemic agents for our knowledge (of single isolated facts); we depend epistemically upon others for our understanding as well.

DEP is intuitively appealing and seems to capture something important about our epistemic practices. As it happens, however, things are more complicated than they initially appear. DEP seems to presuppose that we (can) depend on other epistemic agents for our understanding in the very same way in which we (can) depend on other epistemic agents for our knowledge. But is this presupposition correct?

Many leading epistemologists (including, e.g., Zagzebski 2008; Pritchard 2010; Hills 2016) would probably claim that it is not. As far as knowledge is concerned, I can clearly rely - almost entirely - on the competence and expertise of somebody else. Somebody else might have access to the relevant evidence or might have performed the necessary epistemic work, and given that this person is trustworthy, competent and reliable - and that I know or have good reasons to believe that she is - I can "lean epistemically on her" and enjoy the results of her efforts. Understanding, these authors notice, does not seem to work in this way. Of course, understanding can be facilitated, promoted or fostered. We can do our best to put others in the position to understand. A good teacher, in Zagzebski's words (2008: 145-6), can "recreate the conditions that produce understanding in the hopes that the student will acquire it also". Whether the student actually understands, however, is not up to the teacher. Understanding, or so it seems, is much more similar to a winner shot by a skillful tennis player than to a goal scored on a football field. No doubt Roger Federer owes a great deal to his family and team and to everyone who helped him becoming the player he is. And yet when Roger Federer succeeds in shooting a longline winner in a grand slam final, he is the one to be credited for such an achievement. He does not share the credit for his winner with any particular member of his team cheering from the stands. Out of the metaphor: when I understand something or work something out, this seems to be (entirely) my performance and my accomplishment. Understanding, in contrast to knowledge, is allegedly always an achievement to be credited to the single epistemic agent (Pritchard 2010: 80-3). Call this view the understanding-as-solitary-achievement view. ${ }^{1}$

\footnotetext{
${ }^{1}$ One can understand a variety of different things. A phenomenon or state of affairs $\mathrm{P}$ (for example, the rise in temperature on earth), the reason(s) why $\mathrm{P}$ happened or is the case (for example, why the temperature on earth is rising), the whole subject matter P belongs to (for example, climate change), a representational system such as a scientific theory that has been formulated about $\mathrm{P}$ (for example, the theory of anthropogenic climate change), and much more. It has become standard in the literature in epistemology to assume that, depending on the specific object(s) involved, one achieves a different kind of understanding ( factual, if what is understood is a phenomenon P; explanatory, if what is understood is the reason why $\mathrm{P}$; symbolic, if what is understood is a theory about $\mathrm{P}$; and so on). In what follows, I align with this tradition and focus mainly on factual understanding, i.e., on our understanding directed towards phenomena of reality (this kind of understanding is sometimes called "objectual" in the literature. For reasons that will become clear in section 3, I suggest calling "objectual" only the kind of understanding directed to a domain of phenomena or subject matter). However, it should be noted already at this stage that the distinctions between kinds of understanding typically drawn in the literature turn out on closer inspection to be much fuzzier than they initially appear. (See section 3 and Malfatti 2019a on this.) Understanding the rise in temperature on earth, for example, is typically a matter of mastering the best available theory (or
} 
I am not sure DEP and the understanding-as-solitary-achievement view logically contradict each other; yet there clearly is some form of tension between the two theses. It is hard to see how one could believe that understanding is an achievement always to be credited to the single epistemic agent, while acknowledging that we can depend upon one another for our understanding in the very same way in which we depend upon one another for our knowledge. And on the other hand, it is hard to see how one could defend the claim that one's understanding can be grounded on the epistemic achievement or in the epistemic performance of somebody else, while acknowledging that the single epistemic agent is always to be credited for her understanding.

The overarching aim of this paper is to defend DEP against the understandingas-solitary-achievement view. I start by digging a little bit deeper into the notion of "epistemic dependence" occurring in DEP. I distinguish between three different forms of epistemic dependence relevant for knowledge. I call them phylogenetic, synchronic, and phylogenetic ${ }^{*}$. I then show how all these three forms of dependence apply not only to knowledge, but to understanding as well. If I am right, we have good reasons to think that we do not always deserve the whole credit for everything we understand. Hence, the understanding-as-solitary-achievement view probably ought to be rejected.

\section{The many faces of epistemic dependence}

Consider the following case.

GATE CHANGE: We are both waiting to board our flight at gate C47. I am lost in my own thoughts and not paying particular attention to my surroundings. You are sitting right in front of the screen displaying the information about arrivals and departures (and I know that you are). The screen lies outside my visual field. You look at the screen and come to know that there has been a gate change: our plane will board from gate B74. Before leaving the boarding area, you tell me about the gate change. As a result of your telling, I stand up and go check the screen myself. I form the justified true belief (i.e., come to know) that our plane will board from gate B74, grab my things and head rapidly to Terminal B.

Let me add a few details to this story. You seem to have a clear (although accidental and temporary) epistemic advantage relative to me. You are spatially better located than I am relative to the source of the relevant information. This, however, is not enough to bring me to take your word for it. It is not enough to trigger and ground my (reasonable) trust in you. This is probably because, on the one hand, the stakes are mid-high. If I acted unreflectively upon your telling and you turned out to be wrong, I would probably miss my flight, which is something I would rather avoid. Moreover, you are a complete stranger to me. I am not in the position to make a judgment about your reliability as a testifier. As far as I know, you might be short-sighted. I have no guarantee that you

theories) about it, of having access to the reason(s) why the temperature is rising, and of seeing how the rise in temperature on earth relates to other phenomena belonging to the same domain (for example, the fact that sea levels are rising and desertification is spreading). Given such close interrelations, it seems plausible to assume that much of what I argue in this paper for understanding phenomena will hold also for other understanding-types "in the (conceptual) neighborhood". However, I'll leave the defense of this idea for another project. For this project it is enough to point out that my conception of understanding phenomena is meant to capture the epistemic/cognitive state that matters for the defenders of the understanding-as-solitary-achievement view. (Thanks to an anonymous reviewer of Episteme for pressing me on this point.) 
consulted the screen carefully, and I cannot rule out the possibility that you confused the flight to Hamburg with the one to Strasbourg. I have no conclusive evidence telling me that we are epistemic peers, let alone signalizing that you are my epistemic superior. In light of these considerations, I cannot reasonably take you to speak from knowledge. I cannot assume that your reasons for believing that we will board from gate B74 are better than my reasons for believing that we will board from gate C47 (suppose I not only checked when I arrived at the airport on the screen, but also double checked a little while ago on the company app). I cannot reasonably allow your telling to override my own firmly held belief.

Do I depend upon you for my knowledge? It seems as if in a certain sense I do. Consider the following counterfactual statement:

\section{If you hadn't told me that $p$, I wouldn't have probably come to know that $p$.}

This statement (for $p=$ our flight will board from gate B74) seems to be true of GATE CHANGE. Absorbed in my own thoughts as I was, I probably would not have checked the screen and would have missed my flight if you hadn't told me about the gate change. Your telling, thus, had a very significant causal influence on my actions and put me in the position to gather the evidence that I needed to revise my false belief and to gain the new knowledge. If someone who did not hear your warning and missed the flight waiting to board from gate C47 asked me: "How did you know that the flight was boarding from gate B74?" or "How could you know that the flight was boarding from gate B74, given that the company app was displaying something else?", I would not probably answer "I saw it on the screen" or "It was right there on the screen". I would give you, my informant, the credit that you deserve. I would say something such as: "Somebody told me", or "Somebody told me, and I double checked". Your telling, thus, seems to figure in a good explanation as to why (and how) I obtained the piece of knowledge in question.

And yet there is a sense in which I am not really depending upon you for my knowledge in GATE CHANGE. Your telling was certainly causally relevant in triggering the dynamics of events that eventually resulted in my justified true belief; yet if one asked for an explanation as to why my true belief amounts to knowledge, such an explanation would have nothing to do with you, your epistemic position, your reasons, or your telling. My true belief amounts to knowledge because of reasons that $I$ have and because of evidence that I gathered. My new knowledge, in other words, resulted from epistemic work I performed myself. True, I wouldn't have probably performed the epistemic work in question if I hadn't been lucky enough to run into you - yet the achievement is still mine.

I suggest calling the kind of dependence at play in GATE CHANGE "phylogenetic epistemic dependence". I call it phylogenetic because it concerns the dynamics of events preceding the subject's acquisition of knowledge and because it is a kind of dependence that ceases to exist once the knowledge is acquired. It lies in the past. I take it to be a form of epistemic dependence, because it results in the acquisition of a certain epistemic goal (Broncano-Berrocal and Vega-Encabo 2020: 2745). Clearly, phylogenetic epistemic dependence is not the kind of dependence relevant to the division of epistemic labor. There is no division of epistemic labor going on in GATE CHANGE. You have your reasons for believing $p$ and, given the same perceptual circumstances, I have gathered mine.

Yet this is not the only way I can depend upon another epistemic agent for my knowledge. When a competent, reliable and trustworthy testifier knows something and tells me, I might just reasonably or responsibly believe her. As a result of adopting her view, I might end up "inheriting" the epistemic good from her, i.e., knowing myself. Consider the following case (inspired by true events). 
DESDEMONA'S DEATH: When I arrive at the ticket office at the theater tonight, I find out that the only tickets left for Shakespeare's Othello are "obstructed view tickets". I decide to buy one anyway, thinking: How bad can it be? It turns out to be bad. A massive pillar makes it impossible for me to see anything happening on the right side of the stage. At some point, while I am struggling to keep my eyes open, the old lady sitting next to me - probably moved by compassion - leans toward me and whispers: "Othello just killed Desdemona". She knows this, because she just saw what happened on stage and correctly identified the relevant characters. I take her word for it and, as a result, come to know the relevant content as well.

This case is similar to GATE CHANGE in some respects. Here, too, my informant has a clear epistemic advantage relative to me. The kind old lady is spatially better located than I am relative to the source of the relevant information - i.e., relative to the right side of the stage. I have a massive pillar in my visual field, she - as far as I can tell does not. Hence, she is in the position to see something that I can't see (and I have good reasons to believe that she is).

And yet there are important dissimilarities. The first thing to notice is that the epistemic gap between the old lady at the theater and me is deeper and more substantial than the one between the stranger at the airport and me. In GATE CHANGE, it was very easy for me to stand up, change my spatial location relative to the source of information and gather the relevant evidence myself. This is not something that can be easily done in DESDEMONA'S DEATH. I can't just stand up and move around the audience or invade my neighbors' space to check whether Othello really just killed Desdemona. While waiting to board my flight at the airport, there was firsthand evidence at my fingertips. My neighbor's telling at the theater, on the other hand, is probably the best evidence I can count on for finding out what is currently happening on stage. Another thing to notice is that I don't have any belief or hypothesis whatsoever about what is currently happening on the right side of the stage. I can barely remember the tragedy's plot. By carefully listening to the actor's voices I could have maybe guessed that the two main characters had started to fight - but as I was struggling to stay awake, I don't have those perceptual data available. My neighbor's telling, thus, doesn't have to override any previously firmly held belief. Moreover, the stakes are substantially lower in DESDEMONA'S DEATH than they are in GATE CHANGE. It would surely be a shame to miss the crucial event of Shakespeare's tragedy, but there is not much depending upon this. I don't have to act (nor refrain from acting) on the basis of the information that Othello just killed Desdemona. I wouldn't lose much - neither epistemically nor practically - if the information turned out to be inaccurate. All this explains why accepting my interlocutor's testimony is epistemically appropriate at the theater, while it was not at the airport (the former would be a case of weak deferential acceptance in the terms of Fricker 2009: 233).

Do I depend upon the kind old lady sitting next to me for my knowledge that Othello just killed Desdemona? Yes, significantly so, and differently from how I depended upon my random travel companion in GATE CHANGE. In DESDEMONA'S DEATH, too, my interlocutor's telling is causally relevant to my acquisition of some epistemic good. The old lady's telling has the effect that a new piece of knowledge is acquired. I probably wouldn't have come to know that Othello just killed Desdemona if the old lady hadn't told me this. And yet this is only part of the story. My newly acquired knowledge, differently from in GATE CHANGE, is grounded on the epistemic performance and in the epistemic position of my interlocutor. The old lady saw the scene; I didn't. The old lady has good reasons for believing that Othello just killed Desdemona; I don't. The only reason I have is her telling. Nothing I did contributed in any way to the 
epistemic status of my true belief. I haven't performed any epistemic work myself. I haven't even reflectively chosen my informant - I just happened to be sitting next to her. True, I wouldn't have probably believed my neighbor at the theater if I had spotted possible signs of unreliability or untrustworthiness (for example, I wouldn't have probably believed a 5-year-old child or a visibly drunk person). ${ }^{2}$ And yet I am not the one my knowledge that Othello just killed Desdemona is to be (mainly) credited to. If one asked for an explanation as to why my true belief that Othello killed Desdemona amounts to knowledge, such an explanation wouldn't probably mention me nor my responsible epistemic behavior. It would rather have to do with my informant - her reliability and trustworthiness, her sincerity, her competence, her speaking from knowledge, and so on.

I suggest calling the kind of epistemic dependence instantiated in a case such as DESDEMONA'S DEATH synchronic epistemic dependence. We saw that phylogenetic epistemic dependence is a kind of dependence that concerns the dynamics of events preceding a subject's acquisition of a certain epistemic good, and that it is a kind of dependence that ceases to exist once the good in question is acquired. A subject $S_{1}$ phylogenetically depends upon another subject $S_{2}$ for a certain epistemic good $\mathrm{N}$ when $S_{2}$ (i.e., what $S_{2}$ did or said) put $S_{1}$ in the position to acquire $\mathrm{x}$. Synchronic epistemic dependence, on the other hand, connects the epistemic positions of (at least) two subjects. A subject $S_{1}$ synchronically depends upon another subject $S_{2}$ for a certain epistemic good $\boldsymbol{N}$ when $S_{1}$ 's possession of $\boldsymbol{N}$ depends upon $S_{2}$ 's possession of $\boldsymbol{N}$ or of some essential components thereof. (In our example: I know that Othello just killed Desdemona because the old lady knows, and because her reasons for believing so are good ones.) I take synchronic epistemic dependence to be the kind of dependence widely acknowledged as relevant for the division of epistemic labor. ${ }^{3}$

And yet phylogenetic and synchronic epistemic dependence do not exhaust all the possible ways in which we might depend upon other epistemic agents for our knowledge. Consider the following case.

CRIME SCENE: A woman is found dead in an apartment in London. Scotland Yard asks Sherlock Holmes for help. Having analyzed the scene and briefly checked something on his smartphone, Sherlock comes to know and tells his assistant

\footnotetext{
${ }^{2}$ So, I am acting as a responsible or reliable receiver of testimony (roughly in the sense of Greco 2007). See also Riggs (2009).

${ }^{3}$ An interesting question that arises here is whether synchronic epistemic dependence is instantiated in cases such as the "creationist teacher" case. (Thanks to Finnur Dellsén for raising this issue.) Stella, Lackey's creationist teacher, conveys true, warranted information about evolutionary theory to her students, without endorsing evolutionary theory and therefore without believing any of the theory's claims. As standardly conceived, knowledge implies belief, so Stella does not know, for example, that our planet is approximately six billion years old. However, it seems as if she is successful in bringing her students to believe, and therefore to know, the corresponding proposition. Hence, Lackey concludes, testimony does not just transmit knowledge that is already given; in certain conditions, it works as a generative source of knowledge (Lackey 2007, 2008). Do Stella's students depend synchronically on their teacher for their knowledge or not? Given how I explicated synchronic epistemic dependence, it seems as if they don't. (Stella does not know that $\mathrm{p}$, so her students' knowledge that $\mathrm{p}$ cannot be grounded on Stella's knowledge.) And yet Stella's epistemic position is not as bad as it might seem at first sight. As Lackey construes the scenario, Stella has access to the scientific evidence speaking for the truth of evolutionary theory. This evidence, thus, is in some sense part of her noetic system, despite the fact that she is not responding to it as she should be and cannot bring herself to endorse evolutionary theory. In light of this, it is tempting to claim that in creationist teacher-style cases, synchronic epistemic dependence is instantiated to some extent (epistemic dependence, at the end of the day, is not an all-or-nothing matter) - but I'll have to develop this thought in another project.
} 
John Watson that the victim travelled from Cardiff to London approximately 2, at most 3 hours before her body was found. "Why Cardiff?" asks Watson. "Her coat!" answers Sherlock. "It's slightly damp. She has been in heavy rain in the last few hours - no rain anywhere in London at that time. Under her coat's collar it is damp, too. She has turned it up against the wind. She has got an umbrella in the left pocket, but it's dry and unused. So, not just wind, but strong wind. Too strong to use her umbrella. We know from her suitcase that she intended to stay overnight, so she must have travelled a decent distance, but she could not have travelled longer than 2 or 3 hours because her coat still hasn't dried. Where has there been heavy rain and strong wind in the radius of that travel time? Cardiff."

Sherlock Holmes's track record of discovering truths (especially at crime scenes) is stunningly good, and his less brilliant colleague John Watson knows this. No doubt Sherlock's reasoning abilities and cognitive skills surpass John's by far. In a much less thrilling film adaptation of Sir Arthur Conan Doyle's novel, John would have probably deferred to Sherlock's opinion, and this would have probably been enough for him to come to know that the victim travelled from Cardiff to London a few hours before her body was found. Instead, John demands more from Sherlock. He demands access to Sherlock's grounds for believing what he believes. Sherlock provides such an access. He reconstructs his line of reasoning. He shares his reasons with John. He guides John in appreciating how these reasons support his conclusion. As a result of the interaction with Sherlock, John acquires what we might call "autonomous knowledge". He truly believes that the victim travelled from Cardiff to London a few hours before her body was found, and his belief is grounded on excellent reasons that speak directly for the corresponding content's truth.

Does John depend upon Sherlock for his knowledge that the victim travelled from Cardiff to London a few hours before her body was found $(p)$ ? It seems to me simply undeniable that in some sense he does. But which kind of epistemic dependence is instantiated in CRIME SCENE? Is it phylogenetic? Is it synchronic? It can't be synchronic, because it concerns the dynamics of events preceding John's acquisition of knowledge and it ceases to exist once the new knowledge is acquired. We saw that the new knowledge that John acquires from Sherlock is autonomous. His true belief that $p$ is supported by reasons that he possesses himself and that speak directly for $p$ 's truth. Once the knowledge that $p$ is acquired, John does not depend upon Sherlock anymore. He is not "leaning epistemically" on him. He stands on his own feet, so to say. And yet the epistemic dependence bounding John and Sherlock is not purely phylogenetic either. What Sherlock did in CRIME SCENE is very different from what my random travel companion did in GATE CHANGE. Sherlock did much more than just putting John in the position to know. Sherlock (i.e., what Sherlock said) did not just lead John to gather the relevant reasons himself and to exercise his own cognitive abilities. Sherlock guided John in all the steps of knowledge acquisition. He offered him the end result of his epistemic efforts and showed him how he managed to get there. He is the source of John's true belief that $p$, and for John's reasons in support of $p$.

And the differences between CRIME SCENE and GATE CHANGE run even deeper. Not only would John not have come to know that $p$ if a competent, trustworthy, and reliable testifier such as Sherlock hadn't told him that $p$ (and haven't provided him with reasons for believing $p$ ). John probably wouldn't have come to know that $p$ without Sherlockor, more precisely, without Sherlock's outstanding epistemic performance. Nearly any of Scotland Yard's policemen would have missed the truth in those or similar circumstances. If Sherlock had been sick, or for some reason had refused to help Scotland Yard 
with the investigation, nobody would have probably realized that the victim had travelled from Cardiff to London. Nobody would have pieced together the relevant elements of the crime scene and appreciated how they supported the content in question. It seems thus fair to say that John's knowledge that $p$ is in some sense $d u e$ to Sherlock's epistemic excellence. John knows thanks to Sherlock's outstanding epistemic performance. Is John to be credited for his knowledge that the victim travelled from Cardiff to London a few hours before her body was found? I don't see how this could possibly be the case. Nothing John did - actually, nothing John could have possibly done - contributed to the epistemic status of his true belief. Sherlock made him reach something he would have never reached relying only on his own epistemic strength.

I suggest calling the epistemic dependence instantiated in CRIME SCENE phylogenetic ${ }^{*}$ epistemic dependence. Phylogenetic ${ }^{*}$ epistemic dependence resembles phylogenetic epistemic dependence in that it concerns the dynamics of events preceding a subject's acquisition of a certain epistemic good. But when a subject $S_{1}$ phylogenetically* depends upon another subject $S_{2}$ for a certain epistemic good $\kappa$, (i) $S_{2}$ must have played an essential role in $S_{1}$ 's acquisition of every component of $N$ and (ii) $S_{1}$ 's possession of $x$ must depend on $S_{2}$ 's successful epistemic performance (in the sense that if $S_{2}$ hadn't performed the epistemic work that she performed and hadn't hereby acquired $\mathrm{N}, \mathrm{S}_{1}$ wouldn't possess $\aleph$ ). Is phylogenetic ${ }^{\star}$ epistemic dependence relevant to the division of epistemic labor? If we understand the division of epistemic labor as a matter of relying on the competence and expertise of other epistemic agents both for the possession and in the process of acquisition of epistemic goods, it is hard to deny that it is.

\section{What about understanding?}

I will now try to widen the focus as to comprehend not only knowledge, but also another important epistemic aim, namely, understanding. Do we depend upon other epistemic agents for our understanding? Does understanding allow for a division of epistemic labor as knowledge does?

We saw in the Introduction that answering these questions is not an easy task. On the one hand, it is an undeniable fact about our epistemic practices that understanding, like knowledge, has some kind of social dimension. We acquire understanding on the basis of, or thanks to other epistemic agents' words and practices all the time. Other epistemic agents sometimes play a crucial role in bringing us to understand or in triggering advancements in our understanding of reality. And yet prominent authors claim that there is something peculiar about understanding that makes it impossible for us to "share the burden" of understanding with others as we share it in the case of knowledge. My knowledge can be clearly grounded on and be sustained by the epistemic achievement of somebody else. I can know that $p$, while somebody else is to be (mainly) credited for the knowledge in question. But when I understand something or work something out, or so the understanding-as-solitary-achievement view goes, this accomplishment is to be credited mainly if not entirely to me, as it is due to the successful exercise of my own cognitive abilities (Pritchard 2010: 80-3).

In what follows, I show that we have reasons to think that the understandingas-solitary-achievement view is mistaken. I start by delving into the notion of understanding. I first distinguish between five different types of understanding and then focus on what I call "factual understanding" - i.e., on understanding directed to phenomena or events of reality. I then argue that all the kinds of epistemic dependence I analyzed in section 2 (phylogenetic, synchronic, and phylogenetic ${ }^{\star}$ ) apply not only to knowledge, but to factual understanding as well. If I am right, understanding 
phenomena is not (always) an achievement to be mainly credited to the single epistemic agent who understands.

\subsection{Types and objects of understanding}

So, what is understanding? What does it mean to understand something? Our language use suggests conceiving of understanding as a relation bounding (at least) two elements: a subject (who understands) and an object (which is understood). Our language use tells us also that the objects of understanding form a quite multifaced and heterogeneous crowd. Consider for example the following (epistemically significant) uses of the verb "to understand":

(i) S understands the (apparent) retrograde motion of the planets;

(ii) S understands the Protestant Reformation;

(iii) S understands why sugar dissolves in water;

(iv) $\mathrm{S}$ understands that her partner is mad at her;

(v) S understands phlogiston theory;

(vi) $\ldots$

We talk of understanding, thus, in relation to:

(i) single phenomena or events of reality;

(ii) a domain or subject matter;

(iii) the reason(s) why something happened or is the case;

(iv) single propositional contents;

(v) representational systems;

(vi) ...

Following Baumberger et al. 2017 we might assume that for every epistemically significant language use and depending on the particular object involved there will be a corresponding understanding-type. I suggest to call the understanding directed to single phenomena or events of reality factual understanding; the understanding directed to a domain or subject matter objectual or holistic understanding; the understanding directed to the reason(s) why something is the case explanatory understanding; the understanding directed to single propositional contents propositional understanding; and the understanding directed to representational systems symbolic understanding.

In what follows, I will focus mainly on factual understanding. It is important to point out and to keep in mind, however, that the understanding-types mentioned here are not independent. They are closely interrelated. Factual understanding, for example, typically involves explanatory understanding (Khalifa 2012, 2017; Strevens 2013). It would be very odd to claim that one understands, say, the phenomenon of combustion, if one had no idea whatsoever of the reason(s) why substances burn. ${ }^{4}$ Explanatory understanding, however, is typically not enough for factual understanding - and the reason is that one typically needs objectual understanding to have factual understanding (and vice versa). Understanding a historical event such as the exodus of the Sephardic Jews from the Iberian Peninsula in 1492, for example, depends upon our overall understanding of the historical period of the Reconquista. There is, thus, no understanding of this single historical event without any understanding of the domain or subject matter the event belongs to. We understand the exodus of the Sephardic Jews

${ }^{4}$ There are dissenting voices, however. See, e.g., Lipton (2009) and Dellsén (2020). 
in that we understand the Reconquista. And on the other hand, understanding a subject matter like the Reconquista is a matter of understanding all or at least most of the events comprising it.

\subsection{What is understanding (phenomena)?}

So, what is factual understanding? What does it mean to understand phenomena or events of reality? It is useful to start by noticing that our understanding of phenomena is typically mediated. An epistemic agent typically succeeds in understanding phenomena via or on the basis of certain representational systems which account for these phenomena. I suggest calling the representational systems involved in understanding "epistemic mediators".

Here are a few examples. Climate change scientists understand the rise in temperature on our planet via or on the basis of the theory of anthropogenic climate change. During science class, Kate understands the apparent retrograde motion of the planets via, or thanks to an orrery depicting the solar system. Alison understands the phenomenon of racial segregation via or thanks to Thomas Schelling's model. John understands the phenomenon of superposition via or thanks to Schrödinger's cat thought experiment. Stephen understands the phenomenon of social isolation via or thanks to Edward Hopper's paintings. And so on.

But exactly how and when does an epistemic mediator succeed in providing an epistemic agent with understanding of the phenomena it is about, and it accounts for?

Concerning the how: my suggestion (inspired by Schurz and Lambert's 1994 model; see also Malfatti 2019b) is that for an epistemic mediator EM about a phenomenon P to succeed in providing a subject $\mathrm{S}$ with understanding of or about $\mathrm{P}$, a $\mathrm{P}$-representation $p$ must fit into S's noetic system (or relevant subset thereof) via or thanks to EM. Call this the fitting requirement for understanding.

A couple of clarifications are in order here. First, I suggest understanding "noetic system" quite broadly, as to comprehend not only those informational units the subject judges to be true, but also those informational units the subject accepts or endorses, for example, for practical or cognitive purposes. (I would like to say, for example, that when John understands the phenomenon of superposition on the basis of Schrödinger's cat thought experiment, the thought experiment is in some sense part or "an element" of his noetic system. And yet John is certainly not believing that there is a real cat trapped in a box somewhere in a life-threatening situation.) Second, I should say something about what I mean by "fitting" or bringing a P-representation $p$ to fit (into one's noetic system). The following example might help.

Suppose you learn about the exodus of the Sephardic Jews from the Iberian Peninsula in 1492 (call the corresponding representation $p$ ) from what you take to be an extremely reliable source. In light of your assessment of the source's reliability, you can't do anything but to incorporate $p$ into your noetic system and start believing that (all or most) Sephardic Jews left the Iberian Peninsula in 1492. And yet you are puzzled: you believe (on the basis of what you also take to be reliable sources) that Jews were perfectly integrated within the Spanish society in the 15th century. You also believe that Jews had lived peacefully with the other two religious groups (Islamic and Catholic) for centuries. Something must have changed radically in 1492, but you have no idea what this could be. I would describe a similar situation by saying that $p$ does not fit into your noetic system. On the one hand, $p$ clashes with other things you believe. (One way to make sense of this is by saying that there is a tension at the level of your reasons for and against $p$. Your domain-relative reasons are pulling towards not- $p$, and yet you have meta-reasons - i.e., reasons about the reliability and 
epistemic authority of your source - that pull towards $p$. Or, we might describe this situation saying that what you believe about the relevant subject matter would force you to assign a very low probability to $p$, and yet the fact that you learned about $p$ from a highly reliable source calls for a very different probability assignment.) On the other hand, $p$ is rather isolated in your noetic system. You cannot appreciate how $p$ is to be connected to other things you believe about the relevant subject matter. You are not aware of what $p$ depends upon and of what depends upon $p$. If someone asked you "why $p$ ?" you would have no answer to offer. If someone called $p$ into question and doubted that Jews actually left the Iberian Peninsula in 1492, you wouldn't be able to do anything to change her mind (except trying to convince her to trust your source as well).

Imagine now that you gain access to a historical reconstruction of the relevant period (here an epistemic mediator comes into the picture). You read about the Alhambra Decree and about the Catholic Kings' fight against the "unbelievers". You realize that leaving the Iberian Peninsula wasn't a free choice for Sephardic Jews: they were expelled. Moreover, you realize you were wrong about significant things: Jews hadn't lived peacefully in Portugal and Spain in the centuries before their exodus. They experienced violence and persecutions. Yeshivot were closed and synagogues destroyed. The tensions in your noetic system are now resolved, and the exodus now "makes sense" to you: you can now see it as the culmination of a spiral of intolerance. If someone now asked you "why $p$ ?" you would be able, first and foremost, to point to the immediate cause of the event (the fact that the Alhambra Decree was issued). But you could actually do more than this: you could explain how $p$ fits or is to be embedded into a broader picture. Maybe you could even formulate the plausible hypothesis that many Sephardic Jews would have probably left the Iberian Peninsula at some point anyway during the 15th or 16th century, even if the Catholic Kings wouldn't have signed the Alhambra Decree.

This is what I mean by saying that $p$ fits into your noetic system: $p$ does not clash with other informational units already belonging to your noetic system, and it is connected, in a way that in light of your best evidence you judge as proper, to other informational units that bear on the same subject matter. Prominent authors (such as Grimm 2011; Hills 2016; Elgin 2017) point out that understanding phenomena is not just a matter of believing or endorsing certain contents, but also a matter of being able to do certain things on the basis of what one believes or endorses about a phenomenon or subject matter. The idea of understanding phenomena as a matter of bringing the corresponding representations to fit into one's noetic system does good justice to this intuition. My last example clearly shows that certain abilities (for example, to provide explanations, to make non-trivial inferences, to reason counterfactually) are strongly associated with, or maybe even result from the fulfillment of the fitting requirement.

It is widely acknowledged in the literature (De Regt and Dieks 2005; De Regt 2017; De Regt and Gijsbers 2017) that an epistemic mediator EM accounting for a phenomenon $\mathrm{P}$ must be intelligible to a subject $\mathrm{S}$ for $\mathrm{S}$ to understand $\mathrm{P}$ on the basis of EM. For example, I won't understand the exodus of the Sephardic Jews in 1492 on the basis of a certain historical reconstruction if I don't understand (or if I misunderstand) the reconstruction in question. John can't understand the phenomenon of superposition on the basis of the Schrödinger's cat thought experiment if he doesn't understand the thought experiment itself - what the thought experiment is supposed to represent, how it is to be interpreted, how it relates to real phenomena, and so on. Stephen can't understand the phenomenon of social isolation via or thanks to Edward Hopper's paintings if he doesn't understand (or if he misunderstands) the paintings themselves - if he believes, 
for example, that Hopper aimed at depicting the life in New York City after a zombie apocalypse. We can understand phenomena of reality only via or on the basis of epistemic mediators that we understand. Call this the intelligibility requirement for understanding.

But what does it mean to understand an epistemic mediator? When is an epistemic mediator intelligible to a subject? Before suggesting a tentative answer to these questions, two things are worth noticing. The first is that intelligibility is not merely a property of an epistemic mediator; it is contextual and relational. It depends on the particular subject at play, her epistemic position, her background knowledge and her skills (see De Regt 2017: 103 on this). An epistemic mediator which is intelligible to climate scientists, for example, might not be intelligible to the layperson. The second is that intelligibility is not an all-or-nothing matter. It clearly admits of degrees. I can understand an epistemic mediator more or less, better or worse. Somebody else can understand an epistemic mediator better than I do. I can understand an epistemic mediator $\mathrm{x}$ better than how I understand an epistemic mediator $\mathrm{y}$. I said that an epistemic mediator EM accounting for a phenomenon $\mathrm{P}$ ought to be intelligible to a subject $S$ for $S$ to understand $P$ on the basis of EM. A more precise formulation of this principle would be that an epistemic mediator EM accounting for a phenomenon $\mathrm{P}$ ought to be intelligible to a subject $\mathrm{S}$ to a certain extent for $\mathrm{S}$ to understand $\mathrm{P}$ on the basis of EM. (And it seems plausible that the required degree of intelligibility will be contextually defined, and will depend, among other things, on the particular subject's interests, on the problems that need to be solved, on the tasks that need to be performed, and so on.)

As a criterion for an epistemic mediator's intelligibility I suggest the following: when a subject understands an epistemic mediator EM (to some extent), then S has an accurate mental representation of EM, which, among other things, involves an awareness of how the different parts of EM are related to one another and depend upon one another. Such an awareness will typically result in the subject's ability to use EM effectively - for example, as a basis for inference, prediction, reasoning, and maybe action - within the domain EM is supposed to account for.

Clearly, having access to an intelligible epistemic mediator which enables one to bring certain phenomena (i.e., certain representations thereof) to fit into one's overall worldview might not be enough for one to reach genuine understanding. I won't typically understand the mood swings of my partner on the basis of the horoscope section of today's newspaper - no matter how well I understand the horoscope (or astrology), and how well the horoscope (or astrology) enables me to connect the mood swings in question to other things I believe about my partner's personality. A conspiracy narrative involving bioweapons stolen by Chinese spies in a Canadian lab won't typically be a good basis to understand the origin and spread of COVID-19 - no matter how well one understands such a narrative, and how well the fact that the virus is spreading turns out to fit into one's worldview once one has endorsed it. But why?

The explanation has at least in part to do with the fact that we take understanding phenomena to be a matter of doing one's best, relative to the given epistemic circumstances. In an epistemic environment in which there is a variety of empirically wellgrounded scientific theories about the origin and spread of COVID-19, endorsing a highly improbable conspiracy narrative simply does not strike us as the appropriate or responsible epistemic behavior. We might assume, therefore, that for $\mathrm{S}$ to genuinely understand P via EM, EM must be worthy of being endorsed in the given epistemic circumstances. Given the subject's best evidence and her best judgment, EM must be "at least as good as any available alternative" (in the terms of Elgin 2017: 88; see also Dellsén 2019). Call this the rational endorsement requirement for understanding. 
And yet even the best one can do might not be enough for one to reach genuine understanding. What if, given the best of my evidence and my best judgment, a conspiracy narrative which completely misrepresents the origin and spread of COVID-19 strikes me as at least as good as any available alternative? What if my best available alternative is the best of a bad lot? It is widely acknowledged in the literature that "understanding" denotes a certain kind of epistemic or cognitive success. I think the best way to do justice to this success is by claiming that understanding is a matter of getting things right - in some sense and to a certain extent. If it turned out that everything or most of what a subject believes or endorses about a phenomenon or subject matter is wrong, we certainly would not say that she genuinely understands it. This is why I suggest that for an epistemic mediator EM about a certain phenomenon $\mathrm{P}$ to enable a subject $\mathrm{S}$ to genuinely understand $\mathrm{P}$, most of what $\mathrm{S}$ believes on the basis of EM must be at least approximately true. Call this the adequacy requirement for understanding. ${ }^{5}$

\subsection{Understanding and epistemic dependence}

In section 2, I distinguished between three possible ways in which one can depend upon another epistemic agent for one's knowledge: phylogenetically, synchronically, and phylogenetically*. Do these three forms of epistemic dependence apply to factual understanding as well? In what follows, I'll try to show that they all do.

I claimed that when a subject $S_{1}$ phylogenetically depends upon another subject $S_{2}$ for her knowledge that $p, S_{2}$ plays a relevant causal role in triggering the dynamic of events that results in $S_{1}$ 's knowing that $p$, but $S_{1}$ is to be ultimately credited for her knowledge that $p$. This is because, as far as phylogenetic epistemic dependence is concerned, everything $S_{2}$ does is putting $S_{1}$ in the position to know by herself, by exercising her own cognitive abilities. Can we depend upon other epistemic agents phylogenetically for our understanding? Of course we can. It is trivially possible for other epistemic agents to (intentionally or unintentionally) put us in the position to understand, i.e., to bring us to exercise our own cognitive abilities and, as a result, to reach a state of understanding. Legend has it that the young Werner Heisenberg, walking around one night in the park behind the Copenhagen Institute of Physics, managed to understand something crucial about the structure of microphysical reality while watching a man appearing beneath a streetlamp, disappearing into the darkness, reappearing beneath another lamp and then vanishing back into the dark. Here is how Rovelli (2016: 92) tells this story:

Heisenberg thinks that, 'evidently', the man does not actually vanish and reappear: in his mind, he can easily reconstruct the man's trajectory between one streetlamp and another. After all, a man is a substantial object, big and heavy - and big, heavy objects do not simply appear and vanish ... Ah! These objects, which are substantial, large and heavy, don't vanish and reappear ... but what do we know about electrons? A light flashes on in his mind. Why should small objects such as electrons do the same? What if, effectively, electrons could vanish and reappear? ... What if, between

\footnotetext{
${ }^{5}$ As a side note: the adequacy requirement for understanding does not rule out the possibility that an epistemic mediator which is not true, not truth-apt, or not meant to be true succeeds in providing a subject with genuine understanding of reality. What matters is that the epistemic mediator in question works as a source of approximately true beliefs for the subject, or, in another words, that the subject is able to identify and extract the true information contained within it. This point has been acknowledged and stressed by Greco (2014), Lawler (2019) and Rice (2019), among others.
} 
one interaction with something, and another with something else, the electron could literally be nowhere?

Heisenberg runs back home, starts calculating and gives mathematical substance to his intuition. The first fundamental equations of quantum mechanics are born. "From here on, these equations will do nothing but work, work, work. Up until now, incredible as it may seem, they have never failed" (Rovelli 2016: 92). Suppose now that Heisenberg wouldn't have made that particular step in understanding the microstructure of reality (not on that particular night, at least!) if the man wouldn't have passed through the park. Heisenberg would certainly depend upon the man phylogenetically for his understanding. And yet there is no doubt about the fact that his understanding would remain entirely his own achievement. The credit would be entirely on his side. What the passer-by did was nothing more than (unintentionally) trigger the successful exercise of Heisenberg's cognitive skills. If the random man's (causal) role in Heisenberg's understanding strikes you as negligible or as too marginal to be relevant for phylogenetic epistemic dependence, consider another example. I am currently reading Silence is a Living Thing by Chandra Livia Candiani. A friend gave this book to me - with the intention, I assume, to help me understand something about meditation. If I'll actually understand something about it, my understanding will depend phylogenetically upon my friend; and yet it would be very odd to say that I will share the credit for my understanding of meditation with her. All my friend did was direct my attention towards the right content.

And yet this is clearly not the only way in which we (can) depend upon other epistemic agents for our understanding (of phenomena). Consider phylogenetic ${ }^{*}$ epistemic dependence. While exploring the case of knowledge, I suggested that when a subject $S_{1}$ phylogenetically* depends upon another subject $S_{2}$, the following is the case: first, $S_{2}$ has guided $S_{1}$ in all the steps of the process of knowledge-acquisition; second, $S_{1}$ 's knowledge that $p$ (despite becoming autonomous, i.e., despite being grounded in reasons that $S_{1}$ possesses herself and that speak directly for $p^{\prime}$ 's truth) is in a relevant sense due to $S_{2}$ 's epistemic excellence and/or epistemic performance. Is phylogenetic ${ }^{\star}$ epistemic dependence possible for factual understanding as well? To answer this question, we need to ask ourselves:

(i) Can a subject guide another subject in all the steps of factual understandingacquisition?

(ii) Can a subject's factual understanding be due to another subject's epistemic excellence and/or epistemic performance?

Let me start with (ii). Suppose that in the above-mentioned case CRIME SCENE, Sherlock Holmes doesn't just come to know that the victim travelled from Cardiff to London; he additionally comes up with a theory which correctly accounts for the victim's death. He then shares his thoughts with John Watson. Suppose now that neither John nor any Scotland Yard policeman (nor anyone else) would have been able to formulate the theory that Sherlock managed to formulate. I think it would be fair to say that in a similar case, John's understanding (of the victim's death) would be in a relevant sense due to Sherlock's epistemic excellence. John would understand the victim's death thanks to Sherlock's outstanding epistemic performance.

What about (i)? In section 3.2, I argued that understanding a phenomenon $\mathrm{P}$ requires, in a nutshell, bringing a P-representation $p$ to fit into a subject's noetic system (fitting requirement) via an epistemic mediator EM that is intelligible to the subject (intelligibility requirement), that is rationally endorsable in the given epistemic 
circumstances (rational endorsement requirement), and that works as a basis of approximately true beliefs about the subject matter it is about and it aims at accounting for (adequacy requirement). Can a subject guide another subject to fulfill of all these requirements? It seems to me as if she can.

Take for example the fitting requirement. Suppose you are confronted with a puzzling fact: you read about an invasion of giant locusts in northern Italy (call this phenomenon P). P strikes you as strange or as highly unusual: you would have expected locust invasions to affect barren territories located around the equator, certainly not European countries. Given what you already believe about the relevant subject matter, thus, the P-representation $p$ does not fit into your noetic system. Suppose now that another epistemic agent successfully guides you out of this puzzlement. She tells you why $\mathrm{P}$ probably happened, and why you should have been expecting $\mathrm{P}$ (and phenomena similar to P). Moreover, she helps you appreciate how $p$ is to be connected to other things you already believe or endorse. You were already aware of the fact that climate is changing rapidly and that temperatures on Earth are increasing alarmingly. You just hadn't yet appreciated certain important consequences of this: the fact, for example, that once green and fertile territories such as the Po valley are drying up, and that many animal species are (and probably many more will be) forced to leave their natural habitats and to head north.

Another epistemic agent can guide you in fulfilling the rational endorsement requirement for understanding as well. Suppose, for example, that you come up with and start endorsing a very imaginative theory about P: you think that somebody, probably some powerful companies producing pesticides, intentionally imported giant locusts in the Po valley to create a problem that only they could provide a solution for with the aim of increasing their profits. Suppose now another epistemic agent explains to you that pesticides are not a good solution for locust invasions: they would kill the insects, but they would also poison the soil and presumably compromise the agricultural production for years. Farmers in the Po valley willing to solve the problem of locusts without dramatic side effects, this person tells you, will probably favor and try out other solutions; for example, they will try to increase the population of pheasants - which are locusts' natural predators. Thanks to this information, you realize that releasing a horde of insects in the Po valley would simply make no sense for pesticides companies aiming to increase their profits. Your interlocutor has succeeded in making you realize that the theory that you are endorsing is not a good one; in other words, it is not worthy of being endorsed in the given epistemic circumstances.

Other epistemic agents can play an important role in the fulfillment of the intelligibility requirement as well. An art historian, for example, can certainly help you interpret and understand Edward Hopper's painting Hotel room. An expert in physics can certainly guide you through Schrödinger's cat thought experiment and help you appreciate how the thought experiment relates to and is supposed to instantiate the phenomenon of superposition.

What about the adequacy requirement? I said that for the adequacy requirement to be fulfilled, an epistemic mediator EM accounting for P must work as a source of at least approximately true beliefs about $\mathrm{P}$ for a certain subject. In other words, most of what the subject believes about $\mathrm{P}$ on the basis of EM must be at least approximately true. Extracting truths from an EM, however, won't always be an easy and straightforward process. Suppose you are dealing with an EM which contains idealizations, such as the ideal gas model. The model accounts for gas phenomena by depicting a gas as if it were comprised of dimensionless molecules displaying no mutual attraction. Clearly, there is no such thing. I think that an epistemic agent who understands the ideal gas model better than you do might play a crucial role in your effort of discerning which 
parts of the model are meant as realistic representations of the subject matter and which ones are fictional. Another epistemic agent, therefore, can certainly facilitate the truth-extraction process necessary for the fulfillment of the adequacy requirement for understanding.

All in all, it seems as if phylogenetic ${ }^{\star}$ epistemic dependence applies to knowledge and understanding alike. But when a subject $S_{1}$ phylogenetically ${ }^{\star}$ depends upon another subject $S_{2}$ for a certain epistemic good - or so I argued exploring the case of knowledge it is $S_{2}$ to be (mainly) credited for the achievement gained. If I am right on this, the understanding-as-achievement view is in serious trouble. The credit for our understanding can be (mainly) on someone else's side. Understanding, contrary to what it might seem at first sight, is not an achievement to be mainly credited to the single epistemic agent who understands.

And yet the problems for the understanding-as-solitary-achievement view do not end here. Consider the following case - involving, again, Sherlock Holmes and his less brilliant colleague John Watson.

CRIME SCENE* ${ }^{*}$ A young woman is found dead in her fourth-floor apartment in London. The apartment was apparently locked from the inside, and yet it looks as if the woman was murdered - as her body was hidden in the chimney after she was strangled to death. Scotland Yard asks Sherlock Holmes for help with the investigation. Sherlock analyzes the scene, questions the neighbors, considers and weighs all the possible explanations and comes up with a highly complex theory involving an orangutan on the run who entered the house from the window, killed the woman, tried to hide the body, stole a banana, and then left from the same window. Everything about the scene makes sense on the basis of Sherlock's theory, and the theory is correct. Sherlock shares his thoughts with his assistant John Watson. John understands Sherlock's theory, starts endorsing it, but he trusts Sherlock on something: namely on the fact that his theory contains the best possible explanation for the woman's death.

Does John understand the young woman's death $(\mathrm{P})$ on the basis of Sherlock's theory? It seems to me as if he does. Watson is endorsing a theory about $\mathrm{P}$ which enables him to bring a P-representation $p$ to fit into his noetic system, which correctly accounts for $\mathrm{P}$, which is intelligible to him, and which is rationally endorsable in the given epistemic circumstances.

Does John deserve credit for his understanding? The answer here is probably yes and no. He probably deserves some of the credit, as he had to do something to gain the understanding in question: namely, he had to understand Sherlock's theory. This is not something that anybody else can do for him. And yet I tend to say that the credit is overwhelmingly on Sherlock's side. Sherlock was the one who tracked down and formulated the true theory accounting for the young woman's death by successfully exercising his own cognitive abilities; John had no role whatsoever in this process. Sherlock was the one who evaluated all possible alternative explanatory hypotheses; John did not even try. Sherlock would be able to explain why his theory is to be favored over all of its competitors; John would not. And yet this is not something that John needs to be able to do in this particular context. This is something that John can delegate to Sherlock. The rational endorsement requirement for understanding has it that for a subject to genuinely understand a phenomenon $\mathrm{P}$ via an epistemic mediator EM, EM must be worthy of being endorsed in the given epistemic circumstances. Given the subject's best evidence and her best judgment, EM must be at least as good as any available alternative. Sherlock's theory certainly is worthy of being endorsed in the given epistemic 
circumstances, and John has excellent reasons to believe that it is (among other things, in light of his awareness of Sherlock's outstanding abductive reasoning abilities). John can reasonably and responsibly assume that Sherlock's reasons for endorsing his theory and for believing that his theory is the best of all available alternatives are good ones. So, the rational endorsement requirement for understanding is fulfilled. ${ }^{6}$

We saw that synchronic epistemic dependence connects the epistemic positions of (at least) two subjects. I tend to say that in CRIME SCENE ${ }^{*}$, John's understanding is in some sense connected to and sustained by Sherlock's one. John understands, among other things, because Sherlock understands, and because Sherlock's grounds for endorsing his theory and for believing that his theory is the best of all available alternatives are good ones. If I am right, synchronic epistemic dependence does not apply only to knowledge, but to understanding as well.

\section{Concluding remarks}

The understanding-as-solitary-achievement view has it that when an epistemic agent understands something, this accomplishment is to be credited mainly if not entirely to her, as it is due to the successful exercise of her cognitive abilities. If my arguments in this paper are on the right track, we have good reasons to think that the understanding-as-solitary-achievement view is mistaken. I distinguished between three different ways in which a subject can depend upon another subject for (either the acquisition or the possession of) a certain epistemic good: phylogenetically, synchronically, and phylogenetically* When a subject $S_{1}$ phylogenetically depends upon another subject $S_{2}$ for a certain epistemic good $\kappa, S_{2}$ plays a relevant causal role in $S_{1}$ 's acquisition of $\kappa$, but $S_{1}$ is to be entirely credited for $\kappa$. This is because all $S_{2}$ did was put $S_{1}$ in the position to acquire $N$ herself, by exercising her own cognitive abilities. When the other two kinds of epistemic dependence are instantiated, however, credit attributions look very different. When a subject $S_{1}$ synchronically or phylogenetically* depends upon another

\footnotetext{
${ }^{6}$ This, I suspect, will be the thesis that the defenders of the understanding-as-solitary-achievement view will have the hardest time digesting. They will probably ask: how is it possible for John to reasonably endorse Sherlock's theory (and hence to understand the woman's death) merely by trusting Sherlock on the fact that his theory is the best of all available alternatives? We would expect an "understander" to be able to do much more than this. We would expect an understander to have access to the set of admissible explanations for the phenomenon to be understood, to be able to compare and evaluate these explanations and to pick the one that is best supported by the available evidence (I am assuming that my interlocutor is arguing with Khalifa's model SEEing in the background - see Khalifa 2017: 12). But this is precisely what John can't do. Ergo: he does not reasonably endorse Sherlock's theory, and he does not understand the woman's death. Here is how I would answer to this objection. Why should we demand so much from John? Understanding is not an all-or-nothing matter. It clearly admits of degrees. I am not claiming that John understands the woman's death perfectly, or to the maximum extent possible. John would certainly understand the woman's death better if he were able to do what Sherlock can do - namely, to compare all the admissible explanatory hypothesis and to pick the one best supported by the available evidence. But having (and having grasped) the true theory that contains what is, objectively speaking, the best available explanatory hypothesis for the woman's death seems to be enough for him to reach a certain degree of understanding. If this does not sound plausible enough, consider the following example. Suppose Einstein's theory of general relativity turns out to be the true, final theory about gravity. We understand it and endorse it (among other things, in light of its stunning success in predicting phenomena unknown at the time the theory was formulated). We are working even with the right background knowledge, so that gravitational phenomena make perfect sense via the theory of general relativity in light of what we already believe about reality. Wouldn't it be extremely odd to claim that we don't understand gravity (at all!), because we don't have access to the set of alternative theories of gravity that Einstein considered and ruled out while formulating his own theory?
} 
subject $S_{2}$ for a certain epistemic good $\mathrm{N}, S_{2}$ is to be (mainly) credited for $\mathrm{x}$. I have shown that all three forms of epistemic dependence apply not only to knowledge, but to understanding (phenomena) as well. If I am right, understanding (phenomena) is not always an achievement to be mainly credited to the single epistemic agent who understands.

The ideal of the autonomous knower, who "relies on no one else for any of her knowledge" (Fricker 2009: 225) has long been declared dead. Purifying our epistemic position from the epistemic dependence on others - if feasible at all - is not desirable because of the kind of epistemic state that knowledge is. The ideal of the "autonomous understander", on the other hand, i.e., the ideal of an epistemic agent who relies exclusively on her cognitive faculties and reasoning abilities to make sense of reality, is still living and in good health. But should it be? If my arguments in this paper are on the right track, it probably shouldn't. Understanding is far more social and less autonomous than standardly assumed. ${ }^{7}$

\section{References}

Baumberger C., Beisbart C. and Brun G. (2017). 'What is Understanding?' In S.R. Grimm, C. Baumberger and S. Ammon (eds), Explaining Understanding, pp. 1-34. London: Routledge.

Boyd K. (2017). 'Testifying Understanding.' Episteme 14(1), 123-7.

Croce M. (2018). 'Expert-Oriented Abilities vs. Novice-Oriented Abilities: An Alternative Account of Epistemic Authority.' Episteme 15(4), 476-98.

Broncano-Berrocal F. and Vega-Encabo J. (2020). 'A Taxonomy of Types of Epistemic Dependence: Introduction to the Synthese Special Issue on Epistemic Dependence.' Synthese 197, 2745-63.

De Regt H.W. (2017). Understanding Scientific Understanding. Oxford: Oxford University Press.

De Regt H.W. and Dieks D. (2005). 'A Contextual Approach to Scientific Understanding.' Synthese 144(1), $137-70$.

De Regt H.W. and Gijsbers V. (2017). 'How False Theories Can Yield Genuine Understanding.' In S.R. Grimm, C. Baumberger and S. Ammon (eds), Explaining Understanding, pp. 50-75. London: Routledge.

Dellsén F. (2019). 'Rational Understanding: Toward a Probabilistic Epistemology of Acceptability.' Synthese. https://doi.org/10.1007/s11229-019-02224-7.

Dellsén F. (2020). 'Beyond Explanation: Understanding as Dependency Modelling.' British Journal for the Philosophy of Science 71(4), 1261-86.

Elgin C.Z. (1996). Considered Judgment. Princeton, NJ: Princeton University Press.

Elgin C.Z. (2017). True Enough. Cambridge, MA: MIT Press.

Fricker E. (2009). 'Testimony and Epistemic Autonomy.' In J. Lackey and E. Sosa (eds), The Epistemology of Testimony, pp. 225-53. Oxford: Oxford University Press.

Gordon E. (2017). 'Social Epistemology and the Acquisition of Understanding.' In S.R. Grimm, C. Baumberger and S. Ammon (eds), Explaining Understanding, pp. 293-317. London: Routledge.

Greco J. (2007). 'The Nature of Ability and the Purpose of Knowledge.' Philosophical Issues 17(1), 57-69.

Greco J. (2014). 'Episteme: Knowledge and Understanding.' In K. Timpe and C.A. Boyd (eds), Virtues and their Vices, pp. 284-301. Oxford: Oxford University Press.

\footnotetext{
${ }^{7}$ This paper was meant to be presented at a workshop in Madrid on Epistemic Autonomy organized by Jesús Vega Encabo and planned for March 2020, which unfortunately never took place because of the COVID-19 pandemic. I thank Jesús Vega Encabo anyway for inviting me at the time and for giving me the opportunity to delve into the topic of epistemic autonomy and dependence. I presented early versions of this paper at online events organized by the Humboldt University of Berlin and by the University of Fribourg, and I am very grateful for the excellent feedback I received in both occasions. Thanks also to Michel Croce, Finnur Dellsén, Adham El Shazly, Mario Hubert, Tanja Rechnitzer and the anonymous reviewer of Episteme for the time they dedicated to my paper and for their great comments and suggestions. Finally, thanks to Catherine Z. Elgin and Christoph Jäger for all the extensive discussions on understanding and for being such an outstanding inspiration.
} 
Grimm S.R. (2011). 'Understanding.' In S. Bernecker and D. Pritchard (eds), The Routledge Companion to Epistemology, pp. 84-94. London: Routledge.

Grimm S. (2020). 'Transmitting Understanding and Know-How.' In S. Hetherington and N. Smith (eds), What the Ancients Offer to Contemporary Epistemology, pp. 124-39. London: Routledge.

Hardwig J. (1985). 'Epistemic Dependence.' Journal of Philosophy 82, 335-49.

Hills A. (2016). 'Understanding Why.' Nô̂s 50(4), 661-88.

Jäger C. (2016). 'Epistemic Authority, Preemptive Reasons, and Understanding.' Episteme 13(2), 167-85.

Jäger C. and Malfatti F.I. 2020. 'The Social Fabric of Understanding: Equilibrium, Authority, and Epistemic Empathy.' Synthese. https://doi.org/10.1007/s11229-020-02776-z.

Khalifa K. (2012). 'Inaugurating Understanding or Repackaging Explanation?' Philosophy of Science 79, $15-37$.

Khalifa K. (2017). Understanding, Explanation, and Scientific Knowledge. Cambridge: Cambridge University Press.

Lackey J. (2007). 'Learning from Words.' Philosophy and Phenomenological Research 73, 77-101.

Lackey J. (2008). Learning from Words: Testimony as a Source of Knowledge. Oxford: Oxford University Press.

Lawler I. (2019). 'Scientific Understanding and Felicitous Legitimate Falsehoods.' Synthese. https://doi.org/ 10.1007/s11229-019-02495-0.

Lipton P. (2009). 'Understanding Without Explanation.' In H. de Regt, S. Leonelli and K. Eigner (eds), Scientific Understanding: Philosophical Perspectives, pp. 43-63. Pittsburgh, PA: University of Pittsburgh Press.

Malfatti F.I. (2019a). 'Can Testimony Generate Understanding?’ Social Epistemology 33(6), 477-90.

Malfatti F.I. (2019b). 'On Understanding and Testimony.' Erkenntnis. https://doi.org/10.1007/s10670-01900157-8.

Malfatti F.I. (2020). 'Can Testimony Transmit Understanding?' Theoria 86(1), 54-72.

Pritchard D. (2010). 'Knowledge and Understanding.' In A.A. Millar and A. Haddock (eds), The Nature and Value of Knowledge: Three Investigations, pp. 1-88. Oxford: Oxford University Press.

Rice, C. (2019). 'Understanding Realism.' Synthese. https://doi.org/10.1007/s11229-019-02331-5.

Riggs W. (2009). 'Two Problems of Easy Credit.' Synthese 169(1), 201-16.

Rovelli C. (2016). Reality is Not What it Seems: The Journey to Quantum Gravity. New York, NY: Riverhead Books.

Schurz G. and Lambert K. (1994). 'Outline of a Theory of Scientific Understanding.' Synthese 101, 65-120.

Strevens M. (2013). 'No Understanding Without Explanation.' Studies in the History and the Philosophy of Science 44, 510-15.

Zagzebski L.T. (2008). On Epistemology. Belmont, CA: Wadsworth.

Federica Isabella Malfatti is a postdoctoral researcher at the University of Innsbruck. Her primary research areas are social epistemology and the philosophy of science. Email: fede.malfatti89@gmail.com

Cite this article: Malfatti FI (2021). Do We Deserve Credit for Everything We Understand? Episteme 1-20. https://doi.org/10.1017/epi.2021.14 